\title{
CARACTERIZAÇÃO GEOMORFOLÓGICA E ANÁLISE DE RISCO EM VERTENTE NO BAIRRO DA COMPENSA, MUNICÍPIO DE MANAUS
}

\author{
Liange de Souza Rodrigues ${ }^{(a)}$, Neliane de Souza Alves ${ }^{(b)}$ \\ (a) Secretaria Estadual de Educação (SEDUC-AM), li_rodriguess212@ hotmail.com \\ (b) Escola Normal Superior/Universidade do Estado do Amazonas -UEA, nelis.alves@ gmail.com
}

\section{Eixo: GEOGRAFIA FÍSICA E DESASTRES NATURAIS}

\begin{abstract}
Resumo
As áreas de risco comprendem locais que podem ser atingidos por fenômenos e processos naturais ou induzidos, causando efeito adverso principalmente às pessoas que habitam essas áreas. Sendo assim, o presente trabalho realizado em uma vertente no bairro da Compensa, Zona Oeste da cidade de Manaus, onde se localiza a Comunidade Meu Bem Meu Mal, surgiu com interesse de contribuir na geração de informações para melhor compreensão dos riscos geológicos em escala local, bem como seus fatores condicionantes, agentes deflagadores e os elementos que vivem sob o risco: a Comunidade e o Ambiente fragilizado. Tal interesse surgiu a partir de informações coletadas nos mapeamentos de risco realizados pela CPRM e orgãos parceiros no ano de 2012, que setorizaram as áreas de risco geológico na cidade de Manaus. Foram identificados riscos de deslizamentos na encosta, que geralmente ocorrem nos períodos de maiores precipitações, e as enchentes anuais do Rio Negro.
\end{abstract}

Palavras chave: Área de risco. Encosta. Manaus. Comunidade Meu Bem Meu Mal.

\section{Introdução}

A cidade de Manaus sofreu importantes transformações a partir da década de 1970 com a implantação da Zona Franca de Manaus. $\mathrm{O}$ estabelecimento deste polo industrial gerou vagas de emprego, beneficiando a população da região e ao mesmo tempo constituindo um fator de atração de uma massa de migrantes de considerável proporção, estes provenientes em grande parte do interior do estado.

A oferta de empregos não foi suficiente para grande quantidade de pessoas que imigraram e estas acabaram se estabelecendo na cidade, promovendo processo de ocupação desordenada. Na época, a cidade de Manaus se constituía de terrenos esparsos, dotada de igarapés, com relevo pouco acidentado e com terras pouco disponíveis. As apropiações foram sendo feitas, nas margens dos igarapés em terrenos acidentados, em áreas de infraestrutura básica mínima, ou seja, saneamento, postos de saúde, escolas, energia elétrica ou projetos habitacionais. Situação que perdura até hoje quando nos deparamos com uma cidade mal planejada, mas que aos poucos vem buscando revitalizar áreas degradadas por meio de projetos socioambientais, a exemplo do Programa Social e Ambiental dos Igarapés de Manaus - 
PROSAMIM, que muitas vezes não satisfaz as necessidades do sítio urbano e principalmente da população, que em sua maioria habita áreas suscetíveis a todo tipo de processos naturais e/ou induzidos pelo homem como os desmoronamentos, deslizamentos, erosões e inundações.

A cidade de Manaus, com suas áreas de risco geológico, soma-se a diversas outras cidades brasileiras que enfrentam inúmeros problemas associados ao uso e ocupação inadequados do solo na área urbana. As áreas de risco apresentam somente uma parcela de uma gama de variados temas a serem tratados na cidade onde a população precisa estar associada e atuando ativamente. Problemática não tão simples de ser resolvida, pois diariamente são registrados casos de eventos extremos na cidade, principalmente após as constantes chuvas, normalmente de grande intensidade.

As ocupações desordenadas, que na cidade caracterizam as invasões, representam as áreas mais críticas. As áreas que apresentam os pontos mais suscetívies é a Zona Leste, seguida da Zona Norte e Sul, e a Zona Oeste, onde se localiza o trecho compreendido do bairro da Compensa, objeto de estudo do trabalho, contendo áreas que vão do grau de risco R1 (Baixo) ao R4 (Alto) e também por estar localizado às margens do Rio Negro, na forma de vertentes íngremes e que sofrem a influência anual do regime de cheias deste rio.

\section{Pressupostos Téoricos}

A Geomorfologia é a ciência que estuda as formas do relevo. As formas representam a expressão espacial de uma superfície, compondo as diferentes configurações da paisagem morfológica. É o seu aspecto visível, e a sua configuração, que caracteriza o modelado topográfico da área (CHRISTOFOLETTI, 1980, p.01). Nos estudos urbanos a Geomorfologia assume importância fundamental, pois grande parte dos problemas ambientais nesse meio é resultado de mudanças produzidas pela ação antrópica nas formas, na localização e constituição dos materiais superficiais e nos balanços de processos geomorfológicos. Além da análise do relevo, como ponto específico da ciência, destaca-se o valor dado ao homem como agente modificador e a vulnerabilidade ao qual o meio está suscetível, buscando compreender as relações funcionais dos processos morfodinâmicos, onde a apropriação do relevo como suporte ou recurso antropogênico responde pelos impactos diretos e indiretos, muitas vezes representando derivações com reflexos ambientais, sociais ou mesmo econômicas (CASSETI, 2007, p.5).

Os movimentos de massa induzidos, erosões no solo, inundações e alagamentos fazem parte dos problemas urbanos e também são objetos de estudo da geomorfologia, pois correspondem a mudanças produzidas pela ação humana. Dentro da geormorfologia, um dos ramos que vem chamando atenção da sociedade, em relação às problemáticas enfrentadas atualmente, é a Geormofologia Urbana, que segundo 
Oliveira Jorge (2011, p.117) possui como fator primordial estudos de ações sobre um ambiente artificial, ressaltando a necessidade de explorar essa subdivisão da geormofologia em meio a preocupação com as diversas mudanças que o homem tem provocado no meio, já que grande parte dos problemas enfrentados pela sociedade refere-se a problemas visíveis na cidade.

Em relação às interveções antrópicas no meio, ressalta-se o processo de urbanização brasileira, caracterizado pela apropriação do mercado imobiliário das melhores áreas da cidade, com falta de áreas urbanizada destinadas à moradia popular, resultando na ocupação de áreas ambientalmente frágeis como margens de rios, mangues e encostas íngremes. Esse processo de ocupação teve um curso bastante acelerado no Brasil a partir da década de 1950, desdobrando-se em diversos problemas de ordem ambiental (RODRIGUES; MOROZ-CACCIA GOUVEIA, 2013, p. 69). Como um dos problemas mais comuns e atuantes, em nível nacional, Oliveira Jorge (2011, p.119) destaca os escorregamentos, principalmente de áreas frágeis, atingindo áreas de maior declividade nas cidades, sendo frequentes em locais mais precários, ausentes de infraestruturas, como favelas, loteamentos irregulares e demais formas de assentamento.

\section{- $\quad$ Áreas de Risco}

Segundo o IPT (2007) áreas de risco correspondem a locais passíveis de serem atingidos por fenômenos ou processos naturais e/ou induzidos que causem efeito adverso, sendo que as pessoas que habitam essas áres estão sujeitas a danos de integridade física, perdas materiais e patrimoniais. No contexto das cidades brasileiras, essas áreas correspondem a núcleos habitacionais de baixa renda. Em relação às encostas, os perigos decorrem pelo aumento da suscetibilidade à erosão, especialmente associados aos movimentos de massa (ou deslizamento) e nas terras baixas, às enchentes (COELHO NETTO; AVELLAR, 2007, p.67).

Esses tipos de risco são classificados como riscos geológicos, correspondendo a uma alteração do meio físico sem o pleno conhecimento de suas características geológicas, geotécnicas, adequabilidades e limitações naturais, principalmente em relação ao processo de ocupação do solo de maneira desordenada (PFALTGRAFF et al., 2008 apud TEIXEIRA, 2010).

O risco geológico associa-se à forma de ocupação do homem sobre o terreno, seja em encostas ou em baixadas. No estado do Amazonas as áreas suscetíveis a este tipo de risco estão associadas principalmente à ocupação da rede de drenagem, pois grande parte dos municípios possui sede nas margens de grandes rios. Na cidade de Manaus, além das inundações e erosão da orla fluvial, ocorrem também movimentos de massa, erosão de encostas e assoreamentos (TEIXEIRA, 2010). 
O termo deslizamento corresponde a deslocamentos de massa de solo sobre um embasamento saturado de água, depedendo de vários fatores, tais como: inclinação da vertente, quantidade e frequência das precipitações, presença ou não da vegetação, consolidação do material etc (GUERRA; GUERRA, 2011, p.198). Podendo ser gerado ou induzido pelas atividades do homem, a ocorrência de deslizamento resulta de ocupações inadequadas, sendo mais comum em zonas com ocupações precárias de baixa renda. O escorregamento do tipo induzido é causado pela execução de cortes e aterros inadequados, pela concentração de águas pluviais e servidas, pela retirada da vegetação, e quando ocorre, muitas vezes mobiliza materiais produzidos pela própria ocupação, envolvendo massas de solo de dimensão variadas, lixo e entulho (IPT, 2007).

\section{- $\quad$ Enchentes e inudações}

Nas áreas urbanizadas, as inundações ocorrem quando as águas dos rios, riachos saem de seu leito menor de escoamento e escoa através de seu leito maior que foi ocupado pela população para moradia. Esse processo ocorre quando a precipitação é intensa e o solo não tem capacidade de infiltrar, sendo assim grande parte do volume escoa para o sistema de drenagem, superando a capacidade do leito menor, caracterizando também um processo natural do ciclo hidrológico devido à variabilidade climática (TUCCI, 2005, p.42). As áreas de risco de enchente e inundação correspondem aos terrenos marignais e cursos d'água ocupados por assentamentos habitacionais precários sujeitos ao impacto direto de processo de enchente e inundações.

\section{- Grau e probabilidade do risco}

A definição do grau de probabilidade de risco é importante e serve como base para a metodologia aplicada a análise de risco, a destacar as áreas de risco localizdas em encostas e áreas sujeitas à inundação. O IPT propõe metodologias na qual é feito um roteiro, coletando dados sobre moradia (madeira, alvenaria, etc), a caracterização do local, onde é indicado o grau de inclinção, o fator água, o fator vegetação, além dos sinais de movimentação (feições de instabilidade). Os graus de probabilidade de risco variam de R1 Baixo ou inexistente, R2 Médio, R3 Alto e R4 Muito Alto (CERRI, 2006).

\section{Metodologia}

Para o estudo foi realizado levantamento bibliográfico, levantamento de campo e levantamento topográfico. Além de pesquisas concernentes ao estudo da gemorfologia, com enfase em Geomorfologia Urbana e Geomorfologia de encostas. Dados referentes a mapeamentos de risco geológico na cidade de 
Manaus foram fundamentais para reforçar a identificação de risco existente na encosta. Para os dados do meio físico, foi utilizado sofwtare livre Qgis, na versão 2.8.1, com dados vetoriais (shapes) obtidos nos sites do Intistuto Brasileiro de Geografia e Estatística - IBGE, além de imagens referentes à área para identificação de perídos de cheia e vazante do rio e gráficos indicativos para precipitação, obtidos em site do INMET.

O levantamento de campo objetivou realizar o reconhecimento da área, verificando possibilidade de realização de levantamento topográfico e obtenção de imagens fotográficas referentes à situação de risco e descrição do mesmo.

A utilização da topografia para obtenção de dados do terreno (curvas de nível, declividade e modelo digital do Terreno-MDT) se mostrou um recurso favorável quanto à descrição das variáveis morfométricas do local.

Para o levantamento topográfico foram utilizados Estação Total, GPS Geodésico, dois tripés e taqueômetros. Os dados foram registrados em caderneta de campo. De posse de dados obtidos no levantamento topográfico, foram feitas as etapas de processamento utilizando o software Trimble Business Center, importante para obtenção de coordenadas dos pontos e relatórios de processametno de dados.

Para o processamentos dos pontos coletados utilizou-se do programa DataGeosis Office (Figura 1) para importação de dados, diretamente da estação total. Através do programa são geradas curvas de nível. Com as curvas foi possível extrair o Modelo digital do Terreno (MDT) através do método de triangulação, no qual a declividade é expressa em graus $\left({ }^{\circ}\right)$. 

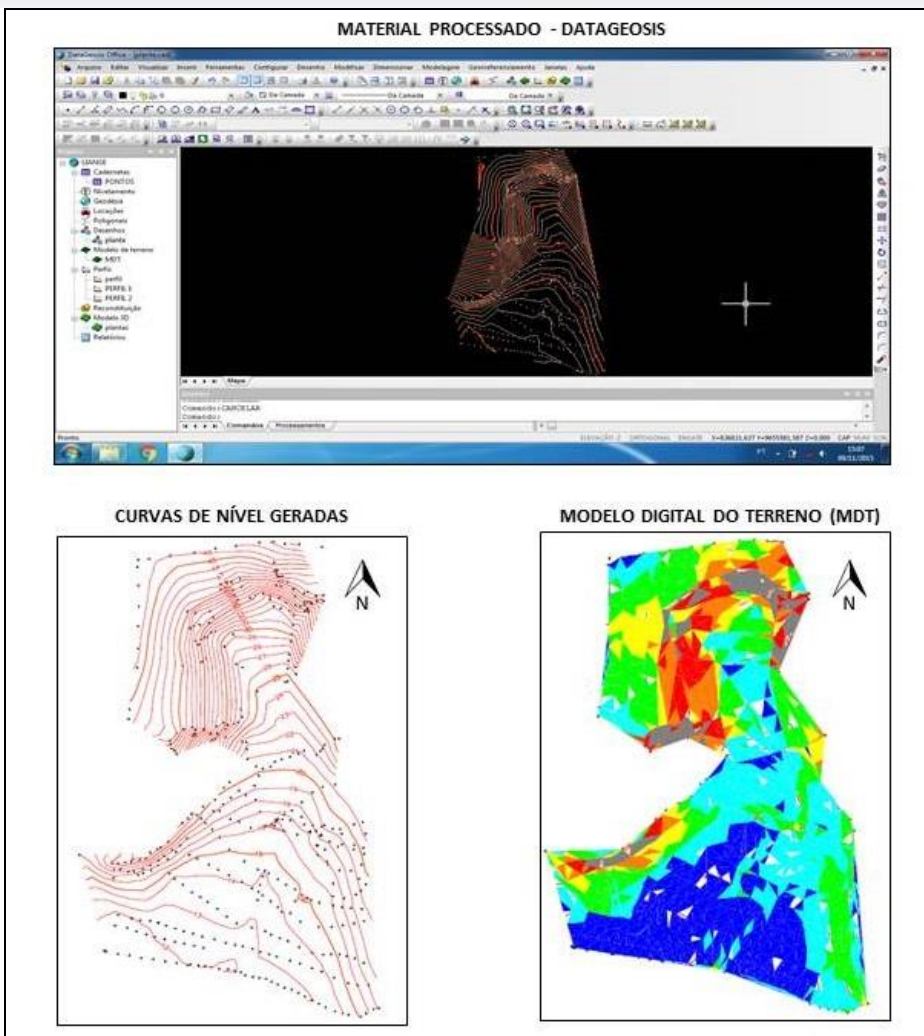

Figura 1 - Processamento de dados no software DataGeosis.

Elaboração: RODRIGUES, L. S., 2015

Para caracterização da encosta e extração de perfis de elevação, foi utilizado o software QGIS e o SIG GRASS-GIS, que gerou os arquivos de Modelo Digital de Elevação - MDE. Com o MDE é possível extrair os perfis do terreno usando a ferramenta Profiles Tools, que é um plugin do QGIS, tornando possível gerar perfis de elevação através de linhas (Figura 2).

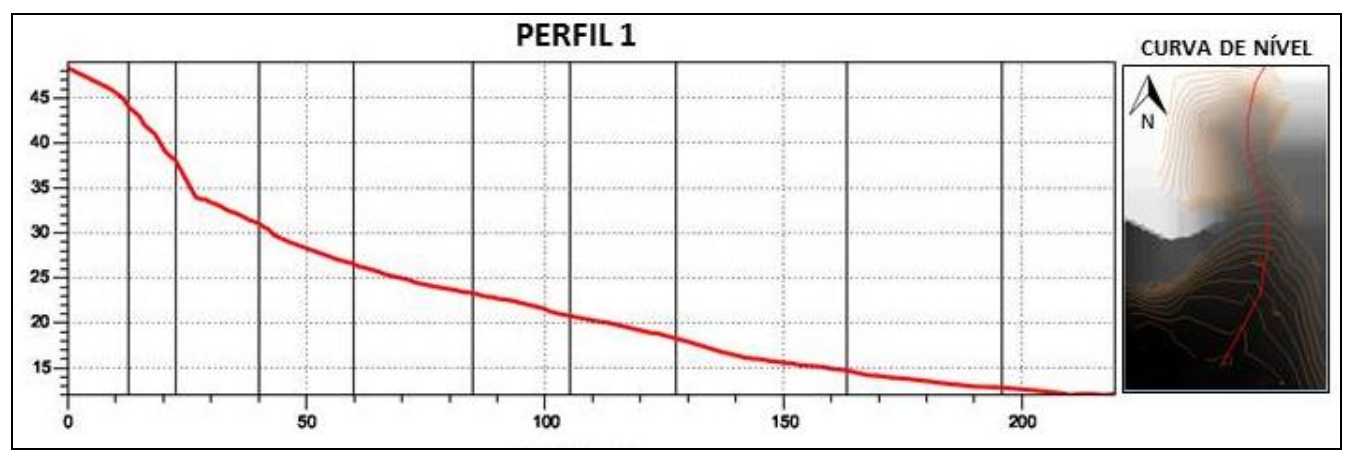

Figura 2 - Perfil de elevação da vertente utilizando o software QGis

Elaboração: RODRIGUES, L. S., 2015 
XVII Simpósio Brasileiro de Geografia Fisica Aplicada

I Congresso Nacional de Geografia Física
OS DESAFIOS DA GEOGRAFIA FÍSICA NA FRONTEIRA DO CONHECIMENTO

Instituto de Geociências - Unicamp

Campinas - SP

28 de Junho à 02 de Julho de 2017

\section{Resultados e Discussões}

De acordo com o mapeamento realizado pelo CPRM (2012), foram identificados áreas de risco geológico na área urbana de Manaus, delimitadas por zonas e setorizadas conforme as ocorrências. O risco na Orla de Manaus foi apresentado em um tópico à parte, sendo identificadas algumas áreas de risco, dentre estas a Comunidade Meu Bem Meu Mal, no Bairro da Compensa (Figura 3).

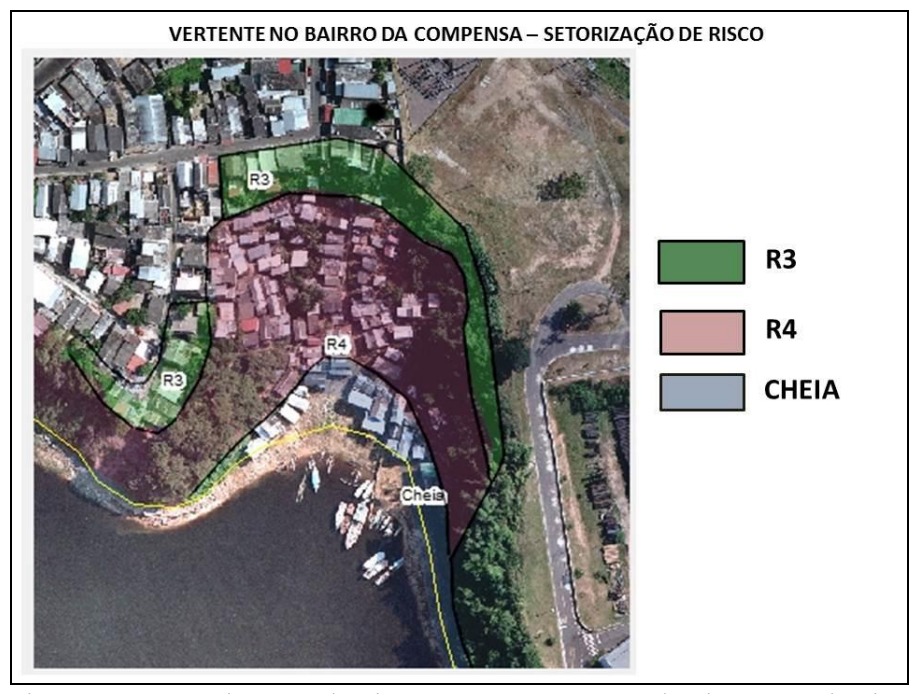

Figura 3 - Setoriazaçã de risco e Mapeamento de risco Geológico

Fonte: Defesa Civil, 2014. Modificado por RODRIGUES, L. S., 2015.

As cheias do Rio Negro ocorrem com regularidade e tem determinado frequentes situações de alertas aos habitantes de Manaus. As populações mais atingidas são principalmente aquelas residentes em áreas susctetíveis a inundações, portanto, impróprias para a ocupação, notadamente junto aos leitos e nas margens dos igarapés e orla ribeirinha do rio Negro (GEOMANAUS, 2002).

\subsection{Caracterização morfológica da vertente}

A morfologia, como uma das variáveis de objeto de estudo da Geomorfologia, oferece subsídios quanto ao tipo de aspectos predominantes na dinâmica do relevo. Obter a forma de uma encosta, por exemplo, auxilia no entendimento dos processos predominantes sobre ela.

Para a determinação da forma da vertente, através da extração de perfis de elevação, foram obtidas seções que caracterizam o perfil em côncavo-convexo. A maior convexidade ocorre na parte superior e maior concavidade na parte inferior. Dependendo do local onde o perfil foi gerado, é possível obter diferentes 
visões sobre a área da vertente. De modo geral, a altimetria está acima dos $45 \mathrm{~m}$, e o comprimento da rampa em torno de $200 \mathrm{~m}$.

De acordo com Bloom (1970) utilizando modelos geométricos de vertente de Troeh (1965), no qual as encostas são divididas em coletoras e distribuidoras de água, o eixo vertical representa as encostas com perfis côncavos que favorecem a lavagem pelas águas da chuva. Logo, a vertente analisada apresenta estes dois tipos de dinâmicas que associadas ao tipo de solo, características da região, a declividade, ao clima e a atividade humana, podem provocar ou acelerar processo atuantes sobre o relevo.

Através do MDT é possível identificar a declividade. O fundo de vale, atingido pelas cheias anuais possui declividades que variam até $20 \%$. As declividades de $20 \%$ a $60 \%$ predominam na parte intermediária e superior da encosta. Valores acima de $60 \%$ indicam os locais, como verificado em campo, de cicatriz de deslizamento e áreas acessíveis por escadarias.

\subsection{Forma de uso e ocupação do solo}

A encosta, na qual está assentada parte da Comunidade Meu Bem Meu Mal se caracteriza por ser uma Área de Preservação Permanente - APP, e que segundo os arts. $2^{\circ}$ e $3^{\circ}$ do Código Florestal Brasileiro (Lei Federal $n^{\circ} 12.651$, de 25 de maio de 2012) se referem a áreas, independentes da cobertura vegetal, com função ambiental de preservar os recursos hídricos, a paisagem, a estabilidade geológica, a biodiversidade, o fluxo gênico de fauna e flora, proteger o solo e assegurar o bem-estar das populações humanas. Para Botelho (2011) a situação das áreas de APPs em áreas urbanas é bastante crítica, o desrespeito às leis que asseguram a preservação da cobertura vegetal nas áreas de cumeadas, altas declividades e margens de rios é frequente.

Quanto à forma de ocupação, no platô predominam habitações do tipo alvenaria, e na encosta há predominância de habitações de madeira, a exemplificar as do tipo palafita (localmente denominada na região), além de habitações mistas, que nas comunidades são comuns, tais como a base de alvenaria e o primeiro piso de madeira. Isso se torna um fator importante na análise de vulnerabilidade do local, pois a qualidade da ocupação indica a menor ou maior resistência aos impactos que ocorrem ou poderão ocorrer. O deslocamento na encosta é feito por meios de becos, escadarias e caminhos improvisados, para facilitar o acesso às moradias. Alguns caminhos apresentam dificuldade, sobretudo devido a declividade do terreno e ao tipo de material utilizado na construção de pontes, na maioria de madeira, que funcionam como caminhos na época das cheias do Rio Negro. 


\section{OS DESAFIOS DA GEOGRAFIA FÍSICA NA FRONTEIRA DO CONHECIMENTO \\ Instituto de Geociências - Unicamp \\ Campinas - SP \\ 28 de Junho à 02 de Julho de 2017}

\subsection{Tipos de Risco na Comunidade Meu Bem Meu Mal}

Na comunidade Meu Bem Meu Mal predominam os risco do tipo deslizamento na vertente e enchentes relacionadas às cheias anuais do rio Negro. Tal fato está associado à dinâmica de fatores naturais, antrópicos ou a ambos. As características dos eventos podem ser identificadas pela predominância de condicionantes que aumentam a suscetibilidade dos elementos de risco (Figura4).

Tabela I - Tipos de Risco e condicionantes identificados na comunidade Meu Bem Meu Mal

\begin{tabular}{|c|c|}
\hline \multicolumn{2}{|c|}{ Tipos de risco e condicionantes } \\
\hline Deslizamento & Enchente \\
\hline $\begin{array}{l}\text { Espacialização de moradias: possibilidade de queda e } \\
\text { atingimento na ocorrência de deslizamentos }\end{array}$ & $\begin{array}{l}\text { Espacialização das moradias: foram feitas } \\
\text { baseadas em níveis comuns de cheias de anos } \\
\text { anteriores. }\end{array}$ \\
\hline $\begin{array}{l}\text { Casas de alvenaria: predominância no platô } \\
\text { (sustenção feita com pilares, tendo sua base no terreno } \\
\text { de declive da encosta), apresenta possibilidade de } \\
\text { queda. } \\
\text { Casas de madeira: apresentam maior possibilidade de } \\
\text { atingimento e maior resistência ao impacto da massa } \\
\text { escorregada. } \\
\text { Ocupações mistas: vulnerabilidade parcial. }\end{array}$ & $\begin{array}{l}\text { Construção de palafitas: habitadas por } \\
\text { moradores residentes no sopé da encosta } \\
\text { Interdições realizadas pela Defesa Civil: } \\
\text { moradias apresentando estruturas vulneráveis. }\end{array}$ \\
\hline $\begin{array}{l}\text { Talude: predominância na comunidade de taludes de } \\
\text { corte, feitos para acomodar habitações. }\end{array}$ & $\begin{array}{l}\text { Uso e ocupação irregular na planície: há } \\
\text { deposição irregular do lixo, que proporcionar } \\
\text { um ambiente fragilizado por conta da poluição } \\
\text { do rio. }\end{array}$ \\
\hline $\begin{array}{l}\text { Lixo: deposição de lixo e entulho em parte íngreme da } \\
\text { encosta e nas partes baixas. A presença de lixo permite } \\
\text { a rápida saturação pela água e excessivo aumento de } \\
\text { peso. }\end{array}$ & $\begin{array}{l}\text { Lixo: favorecimento de acúmulo e aparacimento } \\
\text { de doenças que podem atingir essa população. }\end{array}$ \\
\hline $\begin{array}{l}\text { Vegetação: bananeiras, árvores tipicas de ambitentes } \\
\text { alagáveis e vegetação rasteira. }\end{array}$ & $\begin{array}{l}\text { Cheia e vazante dos rios: influenciam } \\
\text { diretamente na vivência de alguns moradores do } \\
\text { fundo de vale. }\end{array}$ \\
\hline
\end{tabular}




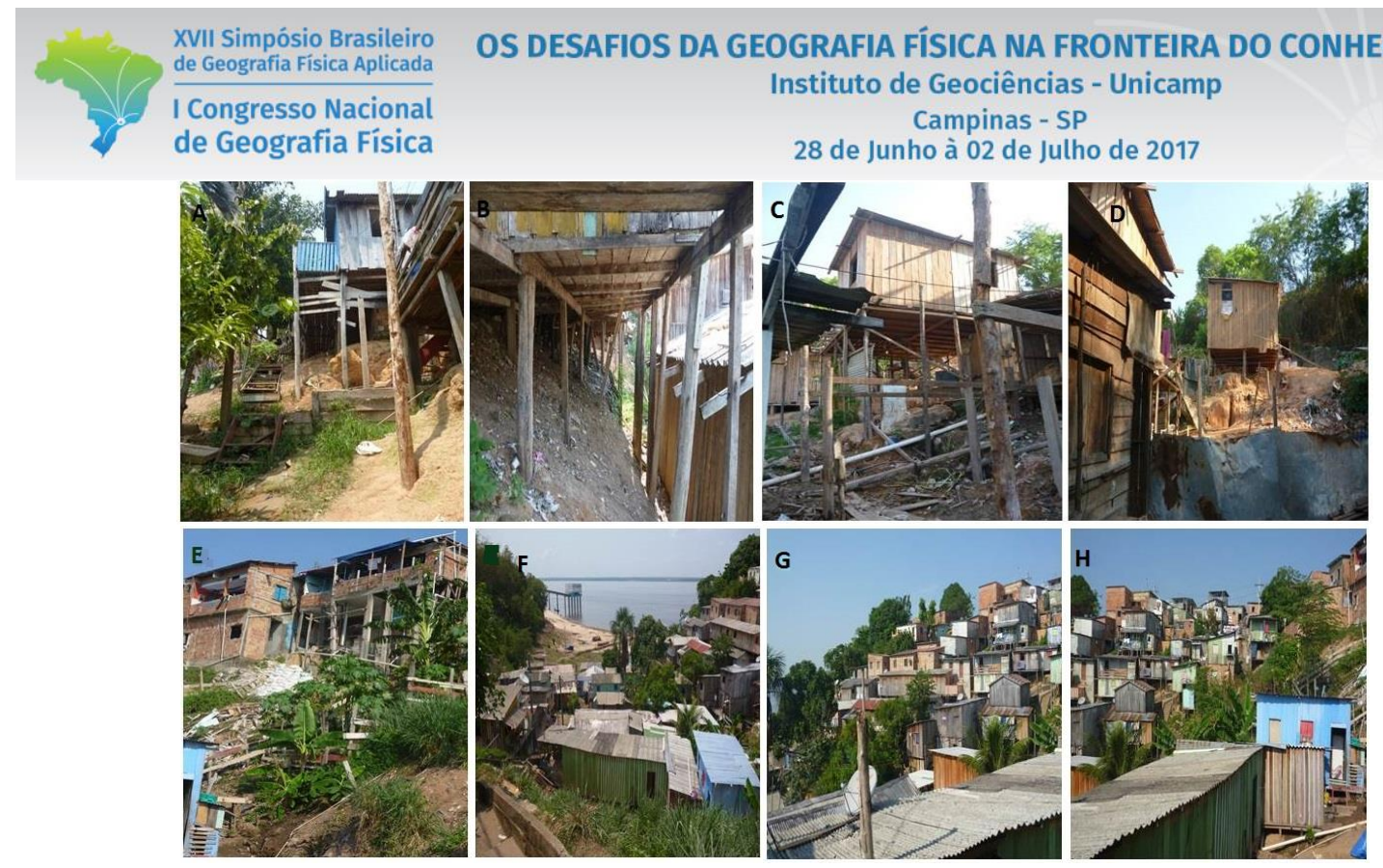

Figura 4 - Cortes feitos no talude para acomodar palafitas (A),(B),(C)e(D); Espacializaçãode moradias de alvenaria e de madeira $(\mathrm{E}),(\mathrm{F}),(\mathrm{G})(\mathrm{H})$.

Organizado por: RODRIGUES, L. S., 2015

A identificação dos riscos geológicos na área da encosta é reforçada por condicionantes naturais e antrópicos. Em relação ao risco de deslizamento, a espacialização das moradias, as modificações feitas nos taludes, presença de lixo e alteração na vegetação reforçam como a população residente auxilia na potencialização de efeitos adversos na encosta. Assim como no risco de enchentes (Figura 5), que apesar, de ser resultado de um processo natural do ciclo hidrológico do rio Negro, afetam os moradores residentes na parte baixa da encosta, que ocupam irregularmente a área.
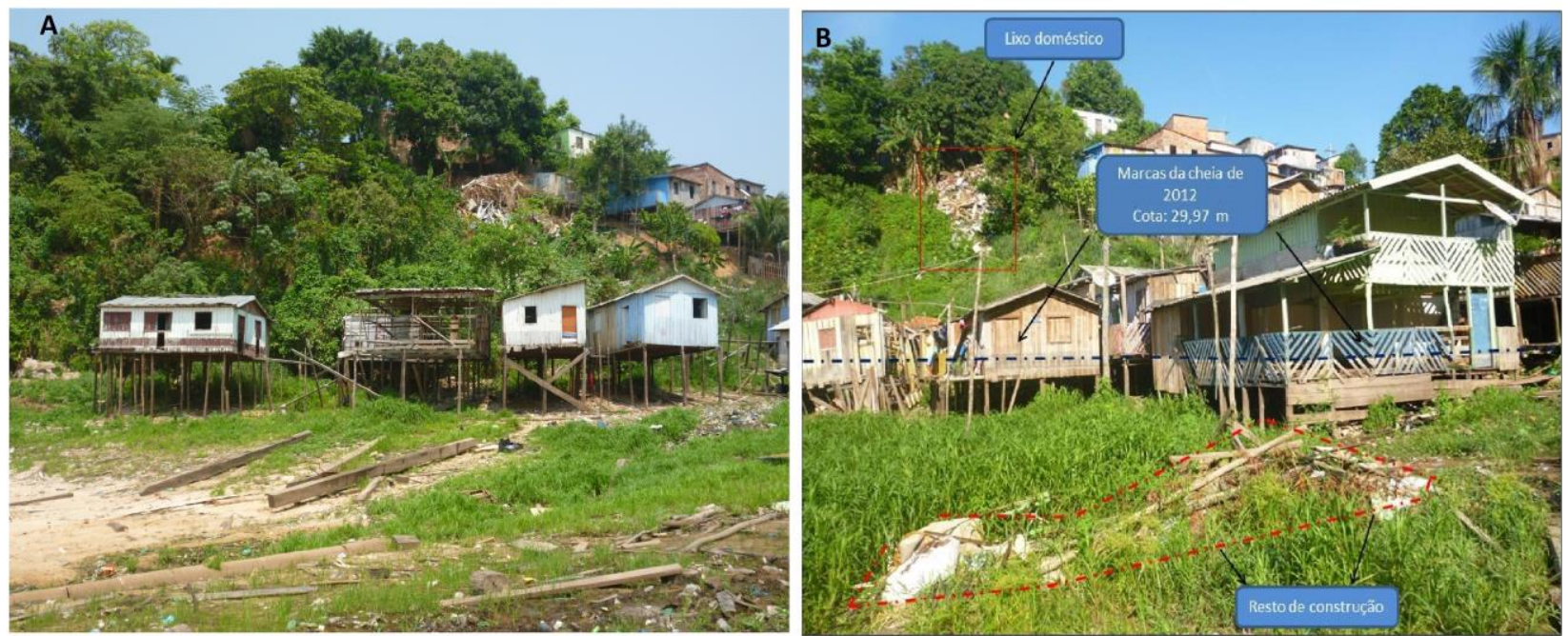

Figura 5 - A) Palafitas interditadas pela Defesa Civil; B) Condicionantes antrópicos ao risco de enchente. Organizado por: RODRIGUES, L. S., 2015. 


\section{OS DESAFIOS DA GEOGRAFIA FÍSICA NA FRONTEIRA DO CONHECIMENTO \\ Instituto de Geociências - Unicamp \\ Campinas - SP \\ 28 de Junho à 02 de Julho de 2017}

\section{Considerações finais}

O presente estudo procurou identificar os fatores que fazem da vertente, localizada na Comunidade Meu Bem Meu Mal no Bairro da Compensa, Zona Oeste da Cidade de Manaus, ser considerada uma área de risco geológico. Os trabalhos de campo e mapeamento realizados possibilitaram a caracterização dos riscos identificados: escorregamentos e/ou deslizamentos de terras e enchentes. Neste estudo foi realizado levantamento topográfico para descrição mais detalhada do terreno, verificação dos tipos de uso e ocupação da vertente.

A identificação dos riscos geológicos na área de encosta é reforçada por condicionantes naturais e antrópicos. Nos condicionantes naturais destaca-se a precipitação da região, o regime hidrológico do rio Negro com seu processo de cheias e vazantes anuais. Os fatores antrópicos indicam a forma como a população residente das áreas auxilia na instabilização da vertente, no risco de deslizamento, pela forma de ocupação no setor íngreme da encosta, pela retirada da vegetação natural e substituição por espécies impróprias para o terreno, pelo tipo de material de construção das habitações e pelo lançamento de águas servidas e lixo na encosta.

Esses fatos reforçam a necessidade de reconhecer os fatores de risco, sua identificação, sobretudo seu gerenciamento. A população reconhece que está em uma área de risco, porém, não possuem meios de habitarem outro local. É importante que ações do poder público sejam executadas, pois as áreas de risco são comumente identificadas em áreas precárias, alocadas em encostas e margens de rios, desprovidos de saneamento. Os mapeamentos são importantes não somente nas medidas de prevenção e monitoramento do risco, mas também na avaliação de impactos ao qual o meio ambiente natural foi submetido se torna importante. No entanto, é preciso levar em consideração a dinamicidade do ambiente e dos processos que neles atuam juntamente às atividades antrópicas, que envolve ações tanto de cunho social, quanto ambiental.

\section{Bibliografia}

BLOOM, A.L. Superfície da terra. São Paulo: Edgard Blücher, 1970.

BOTELHO, R.G.M. Bacias Hidrográficas Urbanas. In: GUERRA, A.J.T. (Org). Geomorfologia Urbana. Rio de Janeiro: Bertrand Brasil, 2011. p. 225-246.

BRASIL. Lei $\mathrm{n}^{\circ} 12.651$, de 25 de maio de 2012. Dispõe sobre a proteção da vegetação nativa; altera as Leis $\mathrm{n}^{\mathrm{os}}$ 6.938, de 31 de agosto de 1981, 9.393, de 19 de dezembro de 1996, e 11.428, de 22 de dezembro de 2006; revoga as Leis nos 4.771, de 15 de setembro de 1965, e 7.754, de 14 de abril de 1989, e a Medida Provisória no 2.166-67, de 24 de agosto de 2001; e dá outras providências. Congresso Nacional, 2012. Disponível em: 〈http://goo.gl/8C928P〉.

Brasil. Ministério das Cidades; IPT - INSTITUTO DE PESQUISAS TECNOLÓGICAS. Mapeamento de riscos em encostas e margem de rios. Brasília: MCidades; IPT, 2007. Disponível em: http://goo.gl/rYX71K.7 
CASSETI, V. (a) Introdução à Geomorfologia. In: CASSETI, V. Geomorfologia. Disponível em: www.funape.org.br/geomorfologia. 2007. Download em: http://www.funape.org.br/geomorfologia/cap1/index.php.

CERRI, L.E.S. 2006. Mapeamento de Riscos nos Municípios. In: CARVALHO, C.S.; GALVÃO, T. (org). Prevenção de Riscos de Deslizamentos em Encostas: Guia para Elaboração de Políticas Municipais, Brasília: Ministério das Cidades; Cities Alliance. Disponível em: http://www.cidades.gov.br/images/stories/ArquivosSNPU/Biblioteca/PrevencaoErradicacao/Livro_Curso_Capacitac ao_Tecnicos_Municipais.pdf

CHRISTOFOLETTI, A. Geomorfologia. São Paulo: Edgard Blucher, 1980.

COELHO NETO, A.L., AVELlAR, A. S. O uso da terra e a dinâmica hidrológica. In: SANTOS, R.F. (Org). Vulnerabilidade Ambiental. Brasília: MMA, 2007. p. 60-73.

CPRM. Mapeamento das áreas de risco geológico da zona urbana de Manaus (AM). Manaus: CPRM, 2012.

GEOMANAUS 2002. Relatório Ambiental Urbano Integrado: informe GEO: Manaus/Supervisão: Ana Lúcia Nadalutti La Rovere, Samyra Crespo: Coordenação: Rui Velloso. Consórcio Parceria, Rio de Janeiro, 21, 1888 pp. Disponível em: 〈http:// goo.gl/lttsrU〉.

GUERRA, A,T., GUERRA, A,J,T. Novo dicionário geológico-geomorfológico. 9. ed. Rio de Janeiro: Bertrand Brasil, 2011.

OLIVEIRA JORGE, M.C. Geomorfologia Urbana: Conceitos, Metodologias e Teorias. In: GUERRA, A.J.T. (Org). Geomorfologia urbana. Rio de Janeiro: Bertrand Brasil, 2011. p. 117-145

RODRIGUES, C. MOROZ-CACCIA GOUVEIA. Importância do fator antrópico na redefinição de processos geomorfológicos e riscos associados em áreas urbanizadas do meio tropical úmido. Exemplos na Grande São Paulo. In: GUERRA, A.J.T., JORGE, M.C.O. (Org) Processos erosivos e recuperação de áreas degradadas. São Paulo: Oficina de Textos, 2013. p. 66-94

TEIXEIRA, S.G. Risco Geológico. In: MAIA, M.A.M, MARMOS, J.L. (Org). Geodiversidade do Estado do Amazonas. Manaus: CPRM, 2010. p. 89-100

TUCCI, C.E.M. Gestão de Inundações Pluviais Urbanas. Ministério das Cidades - Global Water Partnership Wolrd Bank - UNESCO 2005. Disponível em: 〈http:// goo.go/uknxOe>. 